\title{
Extending the Durability of Old Books by Atomized Deacidification and Reinforcement Treatments
}

\author{
Huiming Fan, Mingfeng Guo, Hongyan Mou,* Jianan Liu,* and Jiahe Li \\ Old books suffer from aging and deterioration spurred by acidification, \\ oxidation, and other factors. To preserve these important historical \\ documents, it is important to implement deacidification and reinforcement \\ methods to extend their durability. In this study, microdroplets of $75 \mathrm{~g} / \mathrm{L}$ \\ sodium hydroxide solution were atomized before being utilized to \\ neutralize acidity in the paper. As well, styrene acrylic latex was diluted to \\ 10 times for atomization to function as a reinforcing agent. In addition to \\ studying these methods individually, the effects of simultaneous \\ deacidification and reinforcement were also studied.
}

Keywords: Old books; Papermaking; Deacidification; Reinforcement

Contact information: State Key Laboratory of Pulp and Paper Engineering, South China University of Technology, 510640, Guangdong, China;

*Corresponding authors: fehymou@scut.edu.cn; ppjaliu@scut.edu.cn

\section{INTRODUCTION}

Old books are an important carrier for recording human history and cultural traditions. In addition to being widely used for academic purposes, books are an integral part of many historical relic collections. Due to the degradation of paper over time, some precious original manuscripts have become yellowed, brittle, and riddled with holes, rendering them unreadable. The damage that occurs in old books is mainly due to natural aging, acidification, and oxidation (Area and Cheradame 2011). Such damage generally occurs slowly over time, and any delay in preserving aging books will lead to further damage. Old books are non-renewable, so it is important to maintain their authenticity and original contents, especially for those that exist in limited copies.

Cellulose fibers are the main component of paper. The aging of paper is mainly due to the degradation of cellulose, which hydrolyzes easily in acidic conditions. Acidic substances from hydrolysis of the acetyl groups in the hemicellulose component of the fibers, the adsorption of atmospheric pollutants ( $\left.\mathrm{SO}_{2}, \mathrm{NO}_{\mathrm{x}}\right)$ (Menart et al. 2014), as well as the additives from the papermaking process (Basta et al. 2006) may cause hydrolysis of paper cellulose.

Unbound paper sheets have been conventionally deacidified by their immersion in aqueous solutions containing a $\mathrm{pH}$ buffer compound such as magnesium carbonate followed by drying under constraint to preserve flatness (Baty et al. 2010). Though such procedures are well justified for high-valued items and rare books that need rebinding, there has been a need for rapid methods that do not require the complete wetting of paper. A class of methods known as mass deacidification has been developed and practiced mainly to extend the useful lifetimes of library books (Baty et al. 2010).

The basic principle of the deacidification of old paper is to neutralize the acidic materials present in the surface and interior of the paper. The known mass deacidification 
methods can be roughly classified into gas-phase and liquid-phase methods (Williams and Kelly 1976; Fan and Guo 2018). Known gas-phase deacidification processes include diethyl zinc (DEZ) (Library of Congress 1988; Cunha 1987; Yasue 1997; Zeronian and Needles 1989) and the Book Preservation Associates (BPA) (Cunha 1987) method. The DEZ process, involves the treatment of paper with gaseous diethyl zinc (Zeronian and Needles 1989). The BPA progress involves the treatment of paper with ammonia gas and gaseous ethylene oxide, which react to form ethanolamine, diethanolamine, and triethanolamine (Cunha 1987). The alkali retention after the gas method treatment involving ammonia gas is low (Yan et al. 2016; Fan and Guo 2018). The inefficient alkali retention and safety hazards of gas methods make them not commonly used anymore.

Liquid-phase mass deacidification methods can be regarded as more versatile than the gas-phase methods. Liquid-phase methods mainly include the Wei T'o system (Library of Congress 1988; Cunha 1987; Yasue 1997; Zeronian and Needles1989; Kolar 2008; Brandis 1994) and the Battelle method (Andres et al. 2008). The Wei T'o process involves the treatment of paper with methoxy magnesium methyl carbonate (MMMC) dissolved in a mixture of methanol and freon solvent. The Battelle process can be regarded as a modified Wei T'o process that replaces MMMC by magnesium and titanium ethoxides and the freon solvent by hexamethyldisiloxane (HMDO) (Andres et al. 2008). Besides, in early work at the British Library (Hon 1989; Hubbe et al. 2018) methanol was used as a nonaqueous solvent, and $\mathrm{Ba}(\mathrm{OH})_{2}$ as the alkaline compound to extend the lifetime of paper. But methanol has been found to solubilize some ink components that might do harm to paper protection. The CSC Booksaver system, employing carbonated methyl propoxylate (CMP) in a propanol-fluorocarbon solvent mixture, became available in 2002 (Dupont et al. 2002; Gibert Vives et al. 2004; Wagner et al. 2008; Henniges et al. 2012; Hubbe et al. 2018). The addition of magnesium ions catalyzes the acceleration of cellulose by iron and copper ions natural oxidation (Zeronian and Needles 1989; Kolar et al. 2005). These methods are currently applied in the restoration of acidic books and ancient relics, but they have several unavoidable drawbacks such as powder sediment (Zervos and Moropoulou 2006; Area and Cheradame 2011; Wang et al. 2013).

Another mass deacidification method in current practice uses a suspension of $\mathrm{MgO}$ particles in a nonaqueous carrier liquid (Baty et al. 2010; Jablonsky et al. 2013). This method has demonstrated effectiveness for distribution of the alkaline particles throughout the paper structure, though doubts have been raised regarding the completeness of the deacidification under typical conditions of treatment (Hubbe et al. 2017).

In addition to deacidification, reinforcement is another important factor that must be considered. If an old book is only deacidified, then the damage can only be decelerated and not reversed. A reinforcement process is needed to modify the mechanical performance of an old book to make it strong enough for holding/reading. The reinforcement generally includes the Viennese process (Cunha 1987), organosilane reagent (Ipert et al. 2006; Souguir et al. 2011; Souguir et al. 2012), lamination (Letnar and Vodopivec 1997), sizing/impregnation (Leijonmarck et al. 2013), paper splitting (Galinsky and Haberditzl 2004), and leafcasting (Kruth 1988). By implementing such reinforcement processes, the strength properties of old books can be improved obviously, and this may be a viable alternative or an addition to deacidification process in the preservation of paper.

Up to this point, most of the research done on the preservation of old books has focused on the chemicals used in the process. $\mathrm{NaOH}$ is the well-known strong base, which is beneficial to efficient and rapid deacidification. In the early 2000s, alkaline nanoparticles started to be utilized for deacidification; such work was based on an idea of easy 
penetration into the surface and interior of paper (Giorgi et al. 2005; He et al. 2019). In order to improve the deacidification efficiency, an ultrasonic atomizer, which can make micro-particles (around 4 to $5 \mu \mathrm{m}$ ), could help penetrate deacidifying agent and reinforcing agent into paper.

Based on the results of previous study (Chen et al. 2018), it has been shown that sodium hydroxide can be efficient in deacidification on old books. But the defect of this method is that it is difficult to control the proper dosage and homogenous penetration of $\mathrm{NaOH}$ during treatment process. If the amount of alkaline substances retained in the paper after treatment is too high, then the paper might be damaged. Considering the reasons above, the ultrasonic atomization method was selected in an attempt to improve the uniform penetration of tiny droplets of relatively concentrated $\mathrm{NaOH}$. The operating principle of ultrasonic atomization method requires the use of a relatively concentrated aqueous solution to obtain sufficiently high treatment levels in the paper without excessive moistening (Hanus et al. 2008). Thus the same amount of agent can add more alkaline substances onto paper. The atomization process will inevitably bring in moisture to the paper sheet. This will cause more problems such as forming wrinkles on the paper and even accelerating the hydrolysis of fibers in the natural drying process afterwards. To avoid these problems, it is good to select the higher concentration to bring less moisture in a relatively short period of time. During ultrasonic atomization method deacidification, strict control of $\mathrm{NaOH}$ usage is obtained by controlling the atomization time, because the $\mathrm{pH}$ of treated paper needs to be maintained at 7.0 to 8.0 in order to prevent accelerating airoxidation of paper. Meanwhile, the mechanical strength is not significantly decreased, and the color difference is controlled within 1.5, which can avoid being naked to the naked eye (Chen et al. 2018).

This is the first report of the application of sodium hydroxide with ultrasonic atomization method for the acidification of old books. This work used an ultrasonic atomizer with microdroplets and nanodroplets of deacidifying and reinforcing solutions are applied to old books separately. The deacidification conditions and mechanism was investigated with the aim of achieving good conservation without any damage at room temperature and atmospheric pressure. The degradation of paper fibers from the point of paper structure and the aging principle were also considered in this study.

\section{EXPERIMENTAL}

\section{Materials}

The paper samples were taken from the 1988 Xiangtan University textbook, Environmental Engineering Principles. Sodium hydroxide $(\mathrm{NaOH})$ was purchased from Nanjing Chemical Reagent Co. (Nanjing, China). Styrene acrylic latex was used as the reinforcing agent (Guangzhou Zhencheng Chemical Co., Guangzhou, China). The styrene acrylic latex (Guangzhou Zhencheng Chemical Co., Guangzhou, China) was diluted to one-tenth of the as-received strength before use, with the viscosity of $4.69 \mathrm{cP}$ after mixing at $180 \mathrm{rpm}$.

\section{Paper preparation}

The paper was prepared according to the standard GB/T 450-2008 (2008). To absorb more microdroplets, the paper samples were placed in a vacuum-drying (DZF 6050, China) oven at $40{ }^{\circ} \mathrm{C}$ under a vacuum degree of $0.08 \mathrm{MPa}$ for $12 \mathrm{~h}$ before being 
immediately subjected to ultrasonic atomization (WH-2000, China). The idea was to remove some of the bound and free water, to enable the paper to absorb more microdroplets later in the treatment.

Through the deacidification method, $75 \mathrm{~g} / \mathrm{L}$ of $\mathrm{NaOH}$ solution was used and the diluted styrene acrylic latex was prepared for the strengthening of the paper. The solutions were prepared as microdroplets (around 4 to $5 \mu \mathrm{m}$ ) to penetrate the paper.

Paper can withstand the moisture of atomization for $90 \mathrm{~min}$ as pre-tested (while longer than $90 \mathrm{~min}$, paper started to shrink during the drying process). Too much exposure to moisture will cause the paper to shrink during drying, so it is important to set a time limitation per round, which was chosen as 30 min per round in this paper.

During atomization, two separate fans were used to circulate air if needed. This treatment option will be referred to as the 'fan ventilation'.

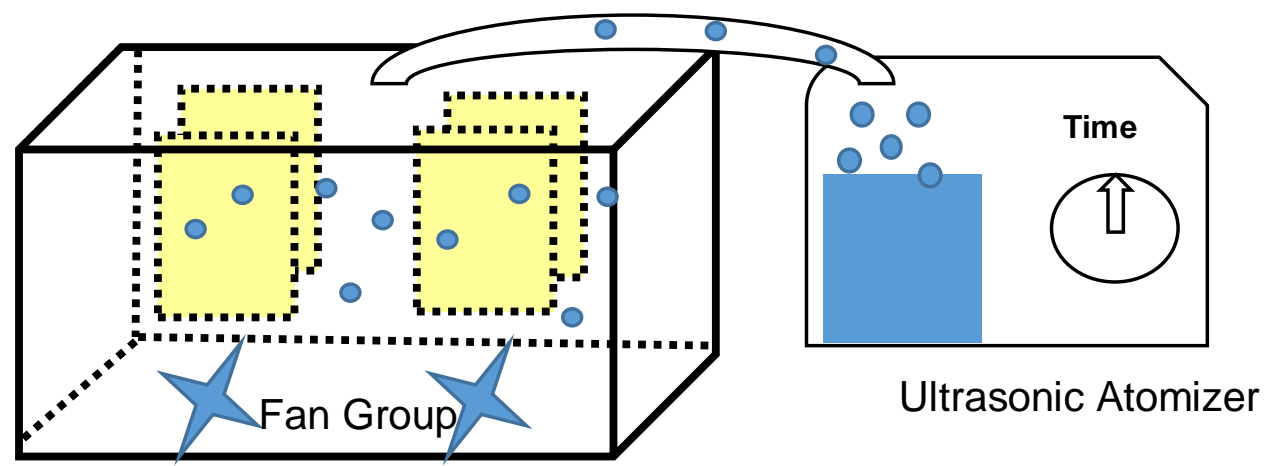

Fig. 1. The designed atomization device

After atomization, the treated samples were naturally air-dried for around $4 \mathrm{~h}$ at room temperature $\left(25^{\circ} \mathrm{C}\right)$. This process prevented the paper from absorbing too much $\mathrm{NaOH}$ and raising the $\mathrm{pH}$ value excessively. The control sample had a $\mathrm{pH}$ value of approximately 4.5 and a machine direction (MD) tensile index of $26.0 \mathrm{Nm} / \mathrm{g}$.

\section{Methods}

Characterization of paper - Determination of $\mathrm{pH}$ on paper surface

To avoid the destructive effects of measurements such as cold extraction, the surface $\mathrm{pH}$ method was utilized in this study (Strlič et al. 2007; Roberson et al. 1976). The $\mathrm{pH}$ value of the paper surface is an important indicator to evaluate the degree of deacidification (Strlič et al. 2007; Xingling et al. 2008). During the test, a drop of distilled water $(0.5 \mathrm{~mL})$ was added on the surface of paper and then put on the flat electrode (planar pH composite electrode, China), each sample was tested 3 times to calculate the results. The Chinese standard GB/T 13528-92 (1992) was used to determine the $\mathrm{pH}$ of the sample.

\section{Determination of machine direction (MD) tensile index of paper}

The samples were placed in an constant temperature and humidity chamber for 24 $\mathrm{h}\left(23 \pm 1{ }^{\circ} \mathrm{C}, 50 \pm 2 \%\right.$ relative humidity (RH)) according to the ISO 187-90 (1990) standard. The tensile strength (L\&W CE062, Sweden) was measured according to the standard GB/T 12914-2008 (2008). Because the fibers were arranged mainly in the MD, the paper strength performance was different in all directions. The tensile strength was tested in the MD and the tensile index was calculated accordingly (Liang et al. 2017). A total of 10 specimens 
of each sample $(100-\mathrm{mm}$-long $\times 15$-mm-wide) were tested to ensure repeatability of the results.

\section{Calculation of paper color difference}

The whiteness, $L^{*}, a^{*}$, and $b^{*}$ values were tested as standard ISO2470-1-2009, (L\&W Elrepho 070, Sweden, R457 D65) before and after atomization were measured using the whiteness meter. The color difference was calculated according to Eq. 1,

$$
\Delta E^{*}=\left(2 \Delta L^{*}+2 \Delta a^{*}+2 \Delta b^{*}\right)^{\frac{1}{2}}
$$

where $\Delta L^{*}$ is the difference in lightness and darkness, $\Delta a^{*}$ is the difference in red and green, $\Delta b^{*}$ is the difference in yellow and blue, and $\Delta E^{*}$ is the total color difference of the sample.

\section{Calculation of relative change $(R C)$ in $\mathrm{pH}$}

The relative change in $\mathrm{pH}$ was calculated to evaluate how efficiently the method neutralized the acidity in the paper. The calculation for relative change in $\mathrm{pH}$ can be seen in Eq. 2,

$$
R C(\%)=\frac{p H \text { of treated paper }-p H \text { of untreated paper }}{p H \text { of untreated paper }} \times 100
$$

where $R C$ is the relative change in $\mathrm{pH}(\%)$.

\section{RESULTS AND DISCUSSION}

\section{Extending the Durability of Old books Using Only the Deacidification Method}

The deacidification mechanism is assumed to involve a neutralization reaction between the acidity in the paper and $\mathrm{OH}^{-}$from the $\mathrm{NaOH}$ in standard conditions. The atomization time of the deacidifying agent was controlled and the fan ventilation was used in combination with the atomization device. The changes in the surface $\mathrm{pH}$ values and deacidification efficiency, MD tensile index, and color difference were determined. Results are shown in Fig. 1, Fig. 2, and Table 3, respectively.
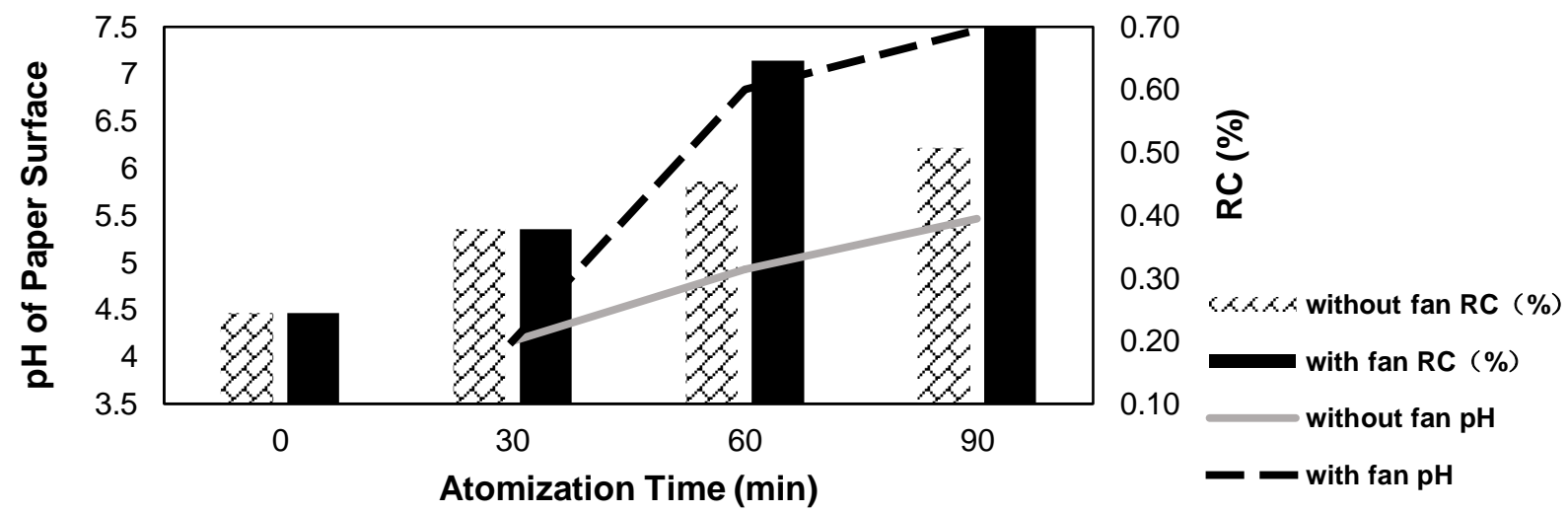

Fig. 2. Effect of $\mathrm{NaOH}$ atomization time on the relative change $(\mathrm{RC})$ in the $\mathrm{pH}$ and the paper surface $\mathrm{pH}$ 


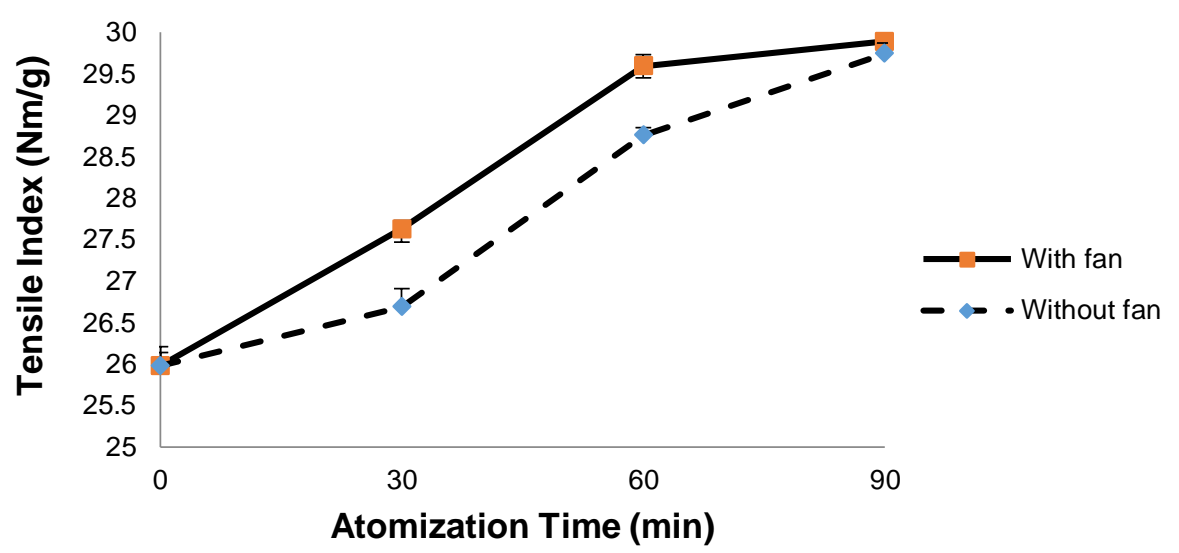

Fig. 3. Effect of $\mathrm{NaOH}$ atomization time on the $\mathrm{MD}$ tensile index

Table 1. Effect of Deacidification Time on Paper Color Difference

\begin{tabular}{|c|c|c|c|c|}
\hline Conditions & $\Delta L^{*}$ & $\triangle a^{*}$ & $\Delta b^{*}$ & $\Delta E^{*}$ \\
\hline Deacidified 30 min & -1.66 & -0.32 & -1.34 & 1.47 \\
\hline Deacidified 60 min & 0.03 & -0.08 & 0.49 & 0.50 \\
\hline Deacidified 90 min & 0.10 & 0.01 & 1.10 & 1.10 \\
\hline
\end{tabular}

The original $\mathrm{pH}$ of the sheet was 4.5, and the original MD tensile index was 26.0 $\mathrm{Nm} / \mathrm{g}$. The post-treatment surface $\mathrm{pH}$ of all samples increased considerably and showed a positive trend with increasing atomization time of $\mathrm{NaOH}$ solution. The surface $\mathrm{pH}$ increased from 4.5 to 7.6 as the atomization time was increased from 0 to $90 \mathrm{~min}$, respectively. As the $\mathrm{pH}$ of paper is being determined by wetted with a drop of water, it is not possible to test local alkaline spots and local acidic spots (Hubbe et al. 2017). It was shown that the neutralization reaction effectively inhibited the acid hydrolysis of cellulose fibers. However, the growth rate leveled off after $60 \mathrm{~min}$ of ultrasonic atomization. The relative change in $\mathrm{pH}$ showed a similar trend of quickly rising from $19 \%$ to $60 \%$ and then slowly rising to $69 \%$. In the initial deacidification stage, neutralization was the dominant reaction that occurred between the alkaline agent and the acidic substances in the paper sheet. While neutralization continued over the course of the reaction, most of the acidic substances were neutralized before the reaction was complete. As the atomization time increased in the later stage, the change of $\mathrm{pH}$ was moderate.

Modification the atomization device with addition of the fan ventilation was found to remarkably improve the uniformity of the atomized droplets, which allowed better dispersity of the microdroplets in the paper sheet. The increase in $\mathrm{pH}$ was also more apparent in the samples with the fan ventilation. There was a positive correlation between the change in $\mathrm{pH}$ and the relative change in $\mathrm{pH}$. After 90 min of atomization, the efficiency of the samples with the fan group was nearly double that of the ones without use of fans. However, this change was not clear when the atomization time was only $30 \mathrm{~min}$, as longer time led to better dispersity. It has been recommended that the $\mathrm{pH}$ values achieved after conservation should be kept in the optimal range of 7.0 to 8.5 (Yueer et al. 2016), where there is an appropriate alkali dosage. Certain alkali reserves in papers can prevent or slow down further hydrolysis of old books by neutralizing the accumulation of acidic substances. 
The use of the fan ventilation allowed the deacidification process to achieve the best preservation range to enhance their durability.

The MD tensile index of the paper also slightly increased accompanying the neutralization, and it was increased by up to $115 \%$ when the atomization time was 90 minutes. Compared to the groups without the fan ventilation, the simultaneous trend in the MD tensile index between the samples with fans also confirmed that the fan ventilation had a beneficial effect on the uniformity. The whole deacidification stage had little effect on the chromatic aberration of the paper, which kept the color change within a range that was hard to be perceived by the naked eye (Chen et al. 2018). With the increased atomization time, more alkaline droplets had penetrated into the paper and neutralized the acidity of paper.

The observed increase in strength can be understood possibly in terms of a localized wetting of spaces between cellulosic fibers. When a film of water becomes established between solid surfaces, it can exert a capillary force that draws the surfaces together (Page 1993). As the water evaporates, the capillary forces draw the surface into molecular contact, allowing new hydrogen bonds to form between the cellulosic surfaces (Campbell 1959). Though the structure of the paper might change in unpredictable ways during partial moistening and redrying, there is a possibility that the final strength can be increased.

Besides, as the fibers absorbed water, and the distance between cellulose got shorter, some hydrogen bonding formed. As a result, the MD tensile index increased in Fig. 3. Moreover, the use of alkaline particles might influence the lignin of paper, which caused the paper color difference.

\section{Extending the Durability of Old books Using Only the Reinforcement Method}

The strength property is important factor for extending the durability of old books Moreover, the effects of the reinforcing agent on the durability of old books were also investigated. The effect of atomization time on the tensile index is shown in Fig. 4. The effects of atomization time on the $\mathrm{pH}$, relative change in $\mathrm{pH}$, and color can be seen in Table 2 .

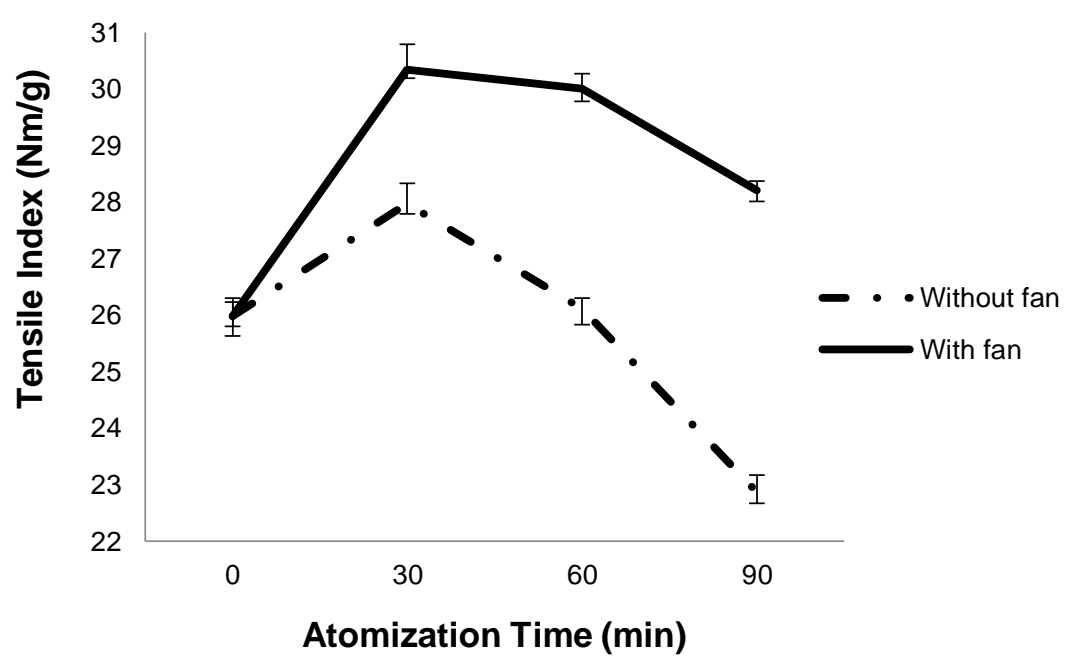

Fig. 4. Effect of the reinforcing agent atomization time on MD tensile index 
Table 2. Effect of the Reinforcing Agent Atomization Time on $\mathrm{pH}, \mathrm{RC}$, and Color Difference

\begin{tabular}{|c|c|c|c|c|c|c|}
\hline Conditions & $\mathrm{pH}$ & $\mathrm{RC}(\%)$ & $\Delta L^{*}$ & $\triangle a^{*}$ & $\Delta b^{*}$ & $\Delta E^{*}$ \\
\hline Reinforced 30 min & 5.33 & 19.51 & -2.26 & -0.45 & -1.07 & 2.54 \\
\hline Reinforced 60 min & 5.23 & 17.26 & 0.08 & -0.27 & -0.82 & 0.87 \\
\hline Reinforced 90 min & 5.09 & 14.13 & -0.06 & -0.36 & -1.52 & 1.56 \\
\hline
\end{tabular}

$\mathrm{RC}=$ Relative change in $\mathrm{pH}$

A reinforcing agent is commonly used for strengthening both in papermaking and for cellulosic materials. It can be impregnated into the fibers to form a film that can cover the paper and modify the fiber surfaces. Moreover, the reinforcing agent is micron-size, has good permeability, and can easily penetrate the inter-fiber layers and gaps to form an adhesive bond. It can easily form a film on the surface of the paper. The addition of a reinforcing agent clearly increased the MD tensile index of the paper, by up to $117 \%$. However, an atomization time past 30 min caused the MD tensile index to decrease due to the accumulated moisture. The concentration of the reinforcing agent was extremely low, approximately $10 \%$, which resulted in a viscosity of $4.69 \mathrm{cP}$ after mixing at $180 \mathrm{rpm}$. As time increased, the paper was exposed to more moisture. In this process, the water molecules destroyed the hydrogen bonds between the cellulose and within the fibers.

The reinforcing agent had a limited effect on increasing the MD tensile index and inhibiting moisture. In contrast, the deacidifying agent alone showed a positive, linear improvement in the MD tensile index (Fig. 4). These results verified the uniform effect of the atomizing treatment when using the fan ventilation.

The reinforcing agent is a weak, alkaline substance, with a $\mathrm{pH}$ value of approximately 9 . The $\mathrm{pH}$ of the paper slightly increased as the reinforcing agent was utilized. However, as the atomization time increased, the moisture content also increased, so the weakly alkaline reinforcing agent provided insufficient alkaline content to neutralize the acidic substances in the paper. As a result, the change in $\mathrm{pH}$ tended to be minor with the change in moisture content. There may be some degree of chromatic aberration change on the paper, but a small chromatic aberration change can be maintained if the humidity is controlled properly.

\section{Extending the Durability of Old Books Based on Both the Deacidification and Reinforcement Methods}

With the use of the fan ventilation, the paper was first deacidified and then reinforced. By controlling the atomization time, the synergistic effect is shown in Table 3 and Table 4. The fan group was used in all of the samples.

Table 3. Effect of Atomization Time on MD Tensile Index

\begin{tabular}{|c|c|c|c|c|}
\hline Conditions & $\begin{array}{c}\text { Not } \\
\text { reinforced }\end{array}$ & $\begin{array}{c}\text { Reinforced } \\
(30 \mathrm{~min})\end{array}$ & $\begin{array}{c}\text { Reinforced } \\
(60 \mathrm{~min})\end{array}$ & $\begin{array}{c}\text { Reinforced } \\
(90 \mathrm{~min})\end{array}$ \\
\hline $\begin{array}{c}\text { Deacidified 30 } \\
\text { min }\end{array}$ & 26.69 & 28.12 & 29.01 & 29.90 \\
\hline $\begin{array}{c}\text { Deacidified 60 } \\
\text { min }\end{array}$ & 28.76 & 29.89 & 30.57 & 30.02 \\
\hline $\begin{array}{c}\text { Deacidified 90 } \\
\text { min }\end{array}$ & 29.74 & 30.17 & 30.94 & 30.15 \\
\hline
\end{tabular}


Table 4. Effect of Atomization Time on Paper $\mathrm{pH}, \mathrm{RC}$, and Color Difference

\begin{tabular}{|c|c|c|c|c|c|c|}
\hline Conditions & $\mathrm{pH}$ & $\mathrm{RC}(\%)$ & $\Delta L^{*}$ & $\triangle a^{*}$ & $\triangle b^{*}$ & $\triangle E^{\star}$ \\
\hline $\begin{array}{l}\text { Deacidified } 30 \mathrm{~min} \\
\text { Reinforced } 30 \mathrm{~min}\end{array}$ & 6.10 & 36.77 & 0.27 & $0 . \overline{10}$ & $0 . \overline{85}$ & 0.90 \\
\hline $\begin{array}{l}\text { Deacidified } 60 \mathrm{~min} \\
\text { Reinforced } 30 \mathrm{~min}\end{array}$ & 7.42 & 66.37 & $\begin{array}{c}- \\
2.37\end{array}$ & $\overline{-}$ & $\begin{array}{c}- \\
0.64\end{array}$ & 2.45 \\
\hline $\begin{array}{l}\text { Deacidified } 90 \mathrm{~min} \\
\text { Reinforced } 30 \mathrm{~min}\end{array}$ & 7.83 & 75.45 & $\begin{array}{c}- \\
1.38\end{array}$ & $\overline{-}$ & $\overline{-}$ & 1.44 \\
\hline $\begin{array}{l}\text { Deacidified } 30 \mathrm{~min} \\
\text { Reinforced } 60 \mathrm{~min}\end{array}$ & 6.26 & 40.36 & 0.38 & $\begin{array}{c}- \\
0.16\end{array}$ & $\begin{array}{c}- \\
0.57\end{array}$ & 0.71 \\
\hline $\begin{array}{l}\text { Deacidified } 60 \mathrm{~min} \\
\text { Reinforced } 60 \mathrm{~min}\end{array}$ & 7.14 & 59.98 & 2. & 0.10 & 0.84 & 2.53 \\
\hline $\begin{array}{l}\text { Deacidified } 90 \mathrm{~min} \\
\text { Reinforced } 60 \mathrm{~min}\end{array}$ & 7.45 & 67.04 & 0.60 & $0 . \overline{0}$ & 0.07 & 0.61 \\
\hline $\begin{array}{l}\text { Deacidified } 30 \mathrm{~min} \\
\text { Reinforced } 90 \mathrm{~min}\end{array}$ & 6.12 & 37.22 & 1.52 & 0.10 & $\begin{array}{c}- \\
0.34\end{array}$ & 1.56 \\
\hline $\begin{array}{l}\text { Deacidified } 60 \mathrm{~min} \\
\text { Reinforced } 90 \mathrm{~min}\end{array}$ & 6.62 & 48.32 & 3.63 & 0.15 & 0.23 & 3.64 \\
\hline $\begin{array}{l}\text { Deacidified } 90 \mathrm{~min} \\
\text { Reinforced } 90 \mathrm{~min}\end{array}$ & 7.08 & 58.74 & $\begin{array}{c}- \\
1.66\end{array}$ & $\begin{array}{c}- \\
0.32\end{array}$ & $\begin{array}{c}- \\
1.34\end{array}$ & 1.47 \\
\hline
\end{tabular}

As shown in Table 3, comparison with the original MD tensile index was $26.0 \mathrm{Nm} / \mathrm{g}$, the samples treated with the deacidification solution in addition to the reinforcing agent yielded stronger paper samples, as the acidity in the paper sheet was thoroughly neutralized (Table 4). Compared to the increased time of deacidification at the same reinforced time, $\mathrm{pH}$ values showed an increasing trend due to the sufficient neutralization. But, with the increased reinforced time, the $\mathrm{pH}$ values were seen to first slightly rise and then to decrease. That might be due to the moisture change of paper and possibly experimental error. The maximum increase in the tensile index $(19.1 \%)$ was found when the paper was deacidified for $90 \mathrm{~min}$ and reinforced for $60 \mathrm{~min}$ (Table 3). The bonding effect of the reinforcing agent was also increased with prolonged time at the same degree of deacidification. However, the tensile index did not always increase with increased reinforcing agent. There was a slight decrease in strength after the moisture content of the paper sheet became saturated. Higher humidity promotes hydrolysis (Graminski et al. 1979; Du Plooy 1981; Zou et al. 1996; Welf et al. 2005). When the atomization time of the reinforcing agent reached 60 min, the strengthening effect of the reinforcing agent reached its maximum benefit.

In Table 4, the difference in paper colors was sporadic and likely due to the degree of aging and the uneven distribution of acidic substances. The deacidification and reinforcement methods influenced the paper color. Generally, if the color difference $\Delta E^{*}$ is less than 1.5, the visual change in the paper color is not recognized by the naked eye (Lin et al. 2018). The use of alkaline particles might influence the lignin of paper to form more chromophoric groups, which caused the paper color difference. Besides, the use of SAE particles might make the paper more blue under the tests, due to its specific film property (Fei et al. 2012). As a result of balance, the color difference showed a slightly increase and after a bit decrease trend.

In addition to removing the acidic substance, the use of the reinforcing agent after the deacidification method can make the paper have better strength behavior to extend its life. This improved the strength, which played a positive role in the durability of the paper. However, with extended reinforcing agent atomization time, the $\mathrm{pH}$ decreased. The $\mathrm{pH}$ and relative change in $\mathrm{pH}$ of the groups that were reinforced longer than $60 \mathrm{~min}$ were 
outperformed by the control group. When the deacidification agent was atomized for 90 min and the reinforcing agent was atomized for $60 \mathrm{~min}$, optimal conditions were achieved. Additionally, the color difference change was only 0.61 , which was hard to detect with the naked eye.

The results of the present work in terms of surface $\mathrm{pH}$, paper strength, and minimal change in appearance can be regarded as encouraging regarding the use of nebulized $\mathrm{NaOH}$ solution droplets and strengthening aid solution droplets for treatment of acidic papers. Future steps in research can include an evaluation of the storage stability. For instance, by use of accelerated aging assays it is possible to estimate the rates of further long-term degradation of paper strength (Zervos and Moropoulou 2006). Such testing is needed to evaluated the hypothesis that nebulized treatment with small droplets of $\mathrm{NaOH}$, with insufficient application amounts to fully wet the paper, is able to achieve comprehensive and uniform neutralization, as well as good resistance to further aging.

\section{CONCLUSIONS}

1. The treatment that combined both deacidification and reinforcement methods was the most effective measure in raising the surface $\mathrm{pH}$ and increasing the paper strength of old books. Such neutralization of $\mathrm{pH}$ can be expected to extend the useful lifetime. The maximum MD tensile index improvement of $19.1 \%$ was seen when using the fan ventilation, atomizing the deacidification agent for $90 \mathrm{~min}$, and atomizing the reinforcing agent for $60 \mathrm{~min}$. If the acid was removed thoroughly via deacidification followed by reinforcing, then the enhanced effect obtained was higher than that of only deacidification or reinforcement.

2. Ventilation with two fans was added to the process to improve the dispersion of the agent. The fan ventilation allowed the $\mathrm{NaOH}$ solution and the reinforcing agent to penetrate the paper sheet more uniformly, neutralizing the acidic substance and forming inter-fiber bonds. The samples with the fan ventilation exhibited a more obvious $\mathrm{pH}$ increase and better relative change in $\mathrm{pH}$ compared to those without the fan ventilation.

3. Variations in paper moisture have an important role in the preservation of old books. As the atomization time progressed, the moisture in the sheet accumulated, resulting in a gentle change in $\mathrm{pH}$. The MD tensile properties of the sheet did not always increase linearly with prolonged reinforcement atomization. At a certain point, the moisture content in the sheet became saturated, which caused a decrease in the MD tensile index. The alkaline hydrolysis of the cellulose was also promoted in this high-humidity and strong alkaline environment. Meanwhile, high moisture makes fibers swell and also accelerate the hydrolysis of fibers, which ultimately led to the decrease in the tensile strength of the paper.

\section{ACKNOWLEDGEMENTS}

The authors are grateful for the funding support of Guangzhou Dadian (GZDD201808), which is committed to extending the durability of old books. 


\section{REFERENCES CITED}

Andres, H., Blüher, A., Grossenbacher, G., Reist, M., Vogelsanger, B., and Wälchli, M. (2008). "The Papersave Swiss - Process quality control and efficacy," Restaurator 29(1), 3-28. DOI: 10.1515/REST.2008.002

Area, M. C., and Cheradame, H. (2011) "Paper aging and degradation: Recent findings and research methods," BioResources 6(4), 5307-5337. DOI: 10.15376/biores.6.4.5307-5337

Baty, J. W., Maitland, C. L., Minter, W., Hubbe, M. A., and Jordan-Mowery, S. K. (2010). "Deacidification for the conservation and preservation of paper-based works: A review," BioResources 5(3), 1955-2023. DOI: 10.15376/biores.5.3.Baty

Basta, A. H., El-Saied, H., Mohamed, S. H., and El-Sherbiny, S. (2006). "The role of neutral rosin-alum size in the production of permanent paper," Restaurator 27(2), 6780. DOI: $10.1515 /$ rest.2006.67

Campbell, W. B. (1959). "The mechanism of bonding," TAPPI 42(12), 999-1001.

Chen, L., and Huang X. X. (2018). "Aging behavior of non-aqueous MgO deacidification system in deacidification of paper archives - A case study of writing paper," Archives of Communications 2018(1), 97-102. DOI: 10.16113/j.cnki.daxtx.2018.01.021

Cunha, G. M. (19987). "Mass deacidification for libraries," Library Technology Reports 23(3), 358-472. DOI: 10.1177/034003520403000106

Du Plooy, A. B. J. (1981). "The influence of moisture content and temperature on the aging rate of paper," Appita 34(4), 287-292. DOI: 10.1515/hfsg.1982.36.6.307

Dupont, A. L., Barthez, J., Jerosch, H., and Lavédrine, B. (2002). "Testing CSC Book Saver®, a commercial deacidification spray," Restaurator 23(1), 39-47. DOI: 10.1515/REST.2002.39

Fan, H. M., and Guo, M. F. (2018). "Discussion on the protection and restoration of ancient books from the perspective of papermaking," China Paper 37(8), 61-65. DOI: 10.11980/j.issn.0254-508X.2018.08.011

Fei, G. Q., Chen, Z. M., Shen, Y. D., Wang, H. H., and Wang, C. Y. (2012). "Synthesis and film properties of self-crosslinking styrene-acrylic latex paper coating agent," Journal of Functional Materials 43(17), 2308-2311. DOI: 10.3969/j.issn.10019731.2012.17.009

Galinsky, E., and Haberditzl, A. (2004). "Paper splitting: Systematisation, quality control and risk minimization," Restaurator 25(3), 171-198. DOI: 10.1515/REST.2004.171

GB/T 450-2008 (2008). "Determination of paper and paperboard specimens and determination of longitudinal, lateral and frontal surfaces of specimens," Standardization Administration of China, Beijing, China.

GB/T 12914-2008 (2008). "Determination of tensile properties," Standardization Administration of China, Beijing, China.

GB/T 13528-1992 (1992). "Determination of pH of paper and board surfaces," Standardization Administration of China, Beijing, China.

Gibert Vives, J. M., Dagà Monmany, J. M., and Areal Guerra, R. (2004). "Nondestructive method for alkaline reserve determination in paper. Diffuse reflectance infrared fourier transform spectroscopy," Restaurator 25(1), 47-67. DOI: 10.1515/REST.2004.47

Giorgi, R., Bozzi, C., Dei, L., Gabbiani, C., Ninham, B. W., and Baglioni, P. (2005). Nanoparticles of $\mathrm{Mg}(\mathrm{OH})_{2}$ : Synthesis and application to paper conservation. Langmuir 21(18), 8495-8501. DOI: 10.1021/la050564m 
Graminski, E. L., Parks, E. J., and Toth, E. E. (1979). "The effects of temperature and moisture on the accelerated aging of paper," in: Durability of Macromolecular Materials, ACS Symposium Series 95, American Chemical Society, Washington, DC, 341-355. DOI: 10.1515/rest.1978.2.3.175

Liang, G. Z., Lu, G., Zhang, J. P., and Zheng, D. Q. (2017). "Research on deacidification of paper based relics using nano-MgO," New Chemical Materials 3, 244-246.

Hanus, J., Bakos, D., Vrska, M., Jablonsky, M., Katuscak, S., Bajzikova, M., Bukovsky, V., and Rychly, J. (2008). "The Kniha Project in Slovakia," in: $2^{\text {nd }}$ International Symposium and Workshops, Durability of Paper and Writing 2, Liubjana, Slovenia, pp. 17-19.

He, B., Lin, Q. X., Chang, M. M., Liu, C.F., Fan, H. M., and Ren, J. L. (2019). "A new and highly efficient conservation treatment for deacidification and strengthening of aging paper by in-situ quaternization," Carbohydrate Polymers 209, 250-257. DOI: 10.1016/j.carbpol.2019.01.034

Henniges, U., Schiehsser, S., Ahn, K., Hofinger, A., Geschke, A., Potthast, A., and Rosenau, T. (2012). "On the structure of the active compound in mass deacidification of paper," Holzforschung 66(4), 447-450. DOI: 10.1515/HF.2011.174

Hon, D. N. S. (1989). “Critical evaluation of mass deacidification processes for book preservation," in: Historic Textile and Paper Materials .II, S. H. Zeronian, and H. L. Needles (eds.), American Chemical Society, Washington, DC. DOI: 10.1021/bk1989-0410.ch002

Hubbe, M. A., Henniges, U., Potthast, A., Ahn, K., and Smith, R. D. (2018).

"Nonaqueous solution deacidification treatments to prolong the storage life of acidic books: A review of mechanistic and process aspects," BioResources 13(3), 70967136.

Hubbe, M. A., Smith, R. D., Zou, X., Katuscak, S., Potthast, A., and Ahn, K. (2017). "Deacidification of acidic books and paper by means of non-aqueous dispersions of alkaline particles: A review focusing on completeness of the reaction," BioResources 12(2), 4410-4477.

Ipert, S., Dupont, A. L., Lavédrine, B., Bégin, P., Rousset, E., and Cheradame, H. (2006). "Mass deacidification of papers and books. IV-A study of papers treated with aminoalkylalkoxysilanes and their resistance to ageing," Polymer Degradation and Stability 91(12), 3448-3455. DOI: 10.1016/j.polymdegradstab.2006.04.033

ISO 187-90 (1990). "Paper, board and pulps - Standard atmosphere for conditioning and testing and procedure for monitoring the atmosphere and conditioning of samples," International Organization for Standardization, Geneva, Switzerland.

Menart, E., de Bruin, G., and Strlič, M. (2014). "Effects of $\mathrm{NO}_{2}$ and acetic acid on the stability of historic paper," Cellulose 21(5), 3701-3713. DOI: 10.1007/s10570-0140374-4

Leijonmarck, S., Cornell, A., Lindbergh, G., and Wågberg, L. (2013). "Single-paper flexible Li-ion battery cells through a paper-making process based on nano-fibrillated cellulose," Journal of Materials Chemistry A 1(15), 4671-4677. DOI: 10.1039/C3TA01532G (Paper) J. Mater. Chem. A, 2013, 1, 4671-4677

Library of Congress. (1988). Book Preservation Technologies, Office of Technology Assessment, Washington, DC, 1988(5), 124. ERIC Number: ED297778

Jablonsky, M., Holúbková, S., Kazíková, J., Botková, M., Ház, A., and Bajzíková, M. (2013). The treatment of acid newsprint paper: Evaluation of treatment by $\mathrm{MgO}$ or by 
a mixture of $\mathrm{MgO}$ and methyl methoxy magnesium carbonate," WoodResearch 58(2), 151-164. ISSN: 13364561

Kolar, J., Možir, A., Balažic, A., Strlič, M., Ceres, G., Conte, V., Mirruzzo, V., Steemers, T., and de Bruin, G. (2008). "New antioxidants for treatment of transition metal containing inks and pigments," Restaurator 29(3), 184-198. DOI:

10.1515/rest.2008.013

Kolar, J., Šala, M., Strlič, M., and Selih, V. S. (2005). "Stabilisation of paper containing iron-gall ink with current aqueous processes," Restaurator 26(3), 181-189. DOI: 10.1515/rest.2005.26.3.181

Kruth, L. M. (1988). "A survey of recent scientific research which has caused are evaluation of commonly used practices in book and paper conservation," The Book and Paper Group Annual 7, 30-39. ISSN:0887-8978:7:0:006

Letnar, M. Č., and Vodopivec, J. (1997). "Protection and conservation of materials on paper. Evaluation of permanence and durability of the laminated material on paper," Restaurator 18(4), 177-190. DOI: 10.1515/rest.1997.18.4.177

Page, D. (1993). "A quantitative theory of the strength of wet webs," J. Pulp Paper Sci. 19(4), J175-J176.

Roberson, D. D. (1976). “The evaluation of paper permanence and durability," TAPPI 59(12), 63-69. ISSN : 0039-8241

Souguir, Z., Dupont, A. L., Fatyeyeva, K., Mortha, G., Cheradame, H., Ipert, S., and Lavédrine, B. (2012). "Strengthening of degraded cellulosic material using a diamine alkylalkoxysilane," RSC Advances 2(19), 7470-7478. DOI: 10.1039/C2RA20957H (Paper) RSC Adv., 2012, 2, 7470-7478

Souguir, Z., Dupont, A. L., d'Espinose de Lacaillerie, J. B., and Cheradame, H. (2011). "Chemical and physicochemical investigation of an aminoalkylalkoxysilane as strengthening agent for cellulosic materials," Biomacromolecules 12(6), 2082-2091. DOI: $10.1021 / \mathrm{bm} 200371 \mathrm{u}$

Strlič, M., Cigić, I. K., Kolar, J., De Bruin, G., and Pihlar, B. (2007). 'Non-destructive evaluation of historical paper based on $\mathrm{pH}$ estimation from VOC emissions," Sensors 7(12), 3136-3145. DOI: 10.3390/s7123136

Wagner, B., Bulska, E., and Sobucki, W. (2008). "Magnesium distribution in paper subjected to deacidification investigated by means of laser ablation inductively coupled plasma mass spectroscopy," Journal of Cultural Heritage 9(1), 60-65. DOI: 10.1016/j.culher.2007.11.001

Wang, Y., Fang, Y., Tan, W., and Liu, C. (2013). "Preservation of aged paper using borax in alcohols and the supercritical carbon dioxide system," Journal of Cultural Heritage 14(1), 16-22. DOI: 10.1016/j.culher.2012.02.010

Welf, E. S., Venditti, R. A., Hubbe, M. A., and Pawlak, J. J. (2005). "The effects of heating without water removal and drying on the swelling as measured by water retention value and degradation as measured by intrinsic viscosity of cellulose papermaking fibers," Progress in Paper Recycling 14(3), 1-9. ISSN: 1061-1452

Williams, J. C., and Kelly, Jr., G. B. (1976). "Method of deacidifying paper," U.S. Patent No. 3969549.

Xingling, T., Xiao, Z., and Feng, G. (2008). "Non-destructive testing and analysis technology in the field of cultural relics protection," Non-destructive Testing 2008(3), 178-182. 
Yan, Y., Yu, H., Yang, G. H., and Tang, Y. (2016). "Research progress in deacidification of paper literature: Multi-functional integrated deacidification agent," Chemical World 2016(12). DOI: 10.19500/j.cnki.0367-6358.2016.12.012

Yasue, A. (1997). "From myth to science: Mass deacidification technology re-examined," IFLA Journal 23(3), 176-179. DOI: 10.1177/034003529702300303

Yueer, Y., Hui, Y., and Huanghui, Y. (2016). "Paper deacidification: Multifunctional and integrated deacidification method," Chemical World 57(12), 806-812.

Zeronian, S. H., and Needles, H. L. (1989). "Historic textile and paper materials. II: conservation and characterization," Historic Textile \& Paper Materials Conservation \& Characterization 1989(4), 590A. DOI: 10.1021/ac00295a804

Zervos, S., and Moropoulou, A. (2006). "Methodology and criteria for the evaluation of paper conservation interventions: A literature review," Restaurator 27(4), 219-274. DOI: 10.1515/REST.2006.219

Zou, X., Uesaka, T., and Gurnagul, N. (1996). "Prediction of paper permanence by accelerated aging. 1. Kinetic analysis of the aging process," Cellulose 3(4), 243-267. DOI: $10.1007 / \mathrm{BF} 02228805$

Article submitted: January 3, 2019; Peer review completed: March 29, 2019; Revised version received and preliminary acceptance: April 17, 2019; Acceptance: April 20, 2019; Published: November 13, 2019.

DOI: $10.15376 /$ biores.15.1.276-289 